wild-type protein, both the LID and the AMPbd mutants decrease the occupancy of the fully folded structure, but they increase the stability of two different states in which either the LID or the AMPbd domain is locally unfolded (Fig. 1). The increased stability of these locally unfolded states stems from the fact that the footprint of a glycine amino-acid residue is smaller than that of other amino-acid residues, which means that the protein chains in the glycine mutants are more flexible than those in the wild-type protein. Remarkably, these two types of local unfolding alter different aspects of the enzyme's function: LID unfolding decreases its binding affinity, whereas AMPbd unfolding increases its activity.

A particularly interesting aspect of the authors' work is that it helps us to understand how surface glycine mutations act at a distance to support cold adaptation. This phenomenon might seem mysterious at first glance, but it is encapsulated in the idea of allosteric regulation ${ }^{4,5}$ - a common form of enzyme regulation in which the binding of a molecular partner at a site distant from the active site affects enzyme activity. The conventional view of allosteric regulation has been that binding of the partner causes small structural changes that propagate through the protein to alter the structure of the active site. However, there is now evidence for mechanisms involving changes in the dynamics (entropy), rather than in the structure, of the unbound state for many cases of allosteric regulation ${ }^{6-8}$. The current work provides striking tests and examples of such entropic allosteric regulation for different enzyme properties.

Saavedra and colleagues' results have substantial implications for the evolution of enzyme function. However, their mechanistic proposal for cold adaptation was tested for just one model enzyme, so its relevance for other cold-adapted enzymes requires further testing. Deeper insight into the biophysical mechanisms of cold adaptation will also benefit from more-detailed views of the structural fluctuations of enzymes afforded by single-molecule experiments ${ }^{9,10}$. Nevertheless, the findings open up new avenues for exploring allosteric control of multiple modes of protein function, both in natural evolution and in rational protein engineering ${ }^{11}$ for biotechnology.

Ashok A. Deniz is in the Department of Integrative Structural and Computational Biology, The Scripps Research Institute,

La Jolla, California 92037, USA.

e-mail:deniz@scripps.edu

1. Saavedra, H. G., Wrabl, J. O., Anderson, J. A., Li, J. \& Hilser, V. J. Nature 558, 324-328 (2018)

2. Siddiqui, K. S. \& Cavicchioli, R. Annu. Rev. Biochem. 75, 403-433 (2006).

3. Fields, P. A. \& Somero, G. N. Proc. Natl Acad. Sci. USA 95, 11476-11481 (1998).

4. Monod, J., Wyman, J. \& Changeux, J. P. J. Mol. Biol. 12, 88-118 (1965).

5. Koshland, D. E. Jr, Némethy, G. \& Filmer, D. Biochemistry 5, 365-385 (1966).

6. Cooper, A. \& Dryden, D. T. F. Eur. Biophys. J. 11, 103-109 (1984).

7. Wand, A. J. Curr. Opin. Struct. Biol. 23, 75-81 (2013).

8. Motlagh, H. N., Wrabl, J. O., Li, J. \& Hilser, V. J. Nature 508, 331-339 (2014)

9. Ferreon, A. C. M., Ferreon, J. C., Wright, P. E. \& Deniz, A. A. Nature 498, 390-394 (2013)

10.Deniz, A. A., Mukhopadhyay, S. \& Lemke, E. A. J. R. Soc. Interface 5, 15-45 (2008).

11.Dokholyan, N. V. Chem. Rev. 116, 6463-6487 (2016)

This article was published online on 6 June 2018.

\title{
How humans and rising seas affect each other
}

The Paris climate agreement aims to limit global warming to no more than $2^{\circ} \mathrm{C}$. An analysis suggests that this will greatly reduce the risks of sea-level rise for coastal communities, but that it will take time to see the benefit.

\section{AIMÉE SLANGEN}

$\longrightarrow$ oastal zones are among the most densely populated areas in the world ${ }^{1}$, but they are threatened by rising sea levels caused by climate change. Writing in Earth's Future, Brown et al. ${ }^{2}$ estimate the impact of sea-level rise in terms of the land area and the number of people exposed, for several scenarios in which global warming is limited to different temperature increases. Their study shows that the amount of exposure to sea-level rise depends on our ability to cap global temperature changes, and that the main benefits of this cap will be seen only after 2100 .

Brown and colleagues began their investigation by simulating how global temperature will change in response to different scenarios of greenhouse-gas emissions, using a simple computational model of the Earth system ${ }^{3}$. They then calculated the global mean sealevel rise that would occur as a result of the projected temperature changes, assuming that the main causes of sea-level rise are the expansion of the volume of ocean water associated with warming, and the melting of land-based ice (that is, ice over land in glaciers, Antarctica and Greenland). To account for the fact that sea-level rise does not occur uniformly across Earth, they then scaled their time series of global mean sea levels with previously reported projections ${ }^{4}$ of regional patterns of sea-level change for 2100 .

In the scenario in which global temperature increases are capped at $1.5^{\circ} \mathrm{C}$ before 2100 , they find a median sea-level rise of 0.4 metres by 2100 and of $1 \mathrm{~m}$ by 2300 . By contrast, in the scenario in which temperatures continue to increase as they are doing now, sea-level rises are $0.8 \mathrm{~m}$ in 2100 and a staggering $4.5 \mathrm{~m}$ in 2300 . These results show that there will be some sea-level rise regardless of efforts to mitigate climate change, because sea levels will not immediately stop rising when the temperature targets are met. However, the effect of capping global temperatures early will be increasingly felt after 2100 and lead to significantly less sea-level rise by 2300 .

In a second step, Brown et al. considered the area of land that has an average chance of being flooded once every 100 years (that is, a
$1 \%$ chance in any given year); such flooding events can be severe (Fig. 1). To do this, they used a database of the world's coastline characteristics ${ }^{5}$, which includes land-elevation data measured by radar. The authors combined the data with their scenarios of sea-level rises, and found that an area of 540,000 square kilometres is already at risk of 1-in-100-year coastal flooding events. For the scenario in which the global temperature rise is mitigated to $1.5^{\circ} \mathrm{C}$, this area increases to $620,000 \mathrm{~km}^{2}$ by 2100 , and to $702,000 \mathrm{~km}^{2}$ by 2300 (values correspond to the 50th percentile of the range of predicted values for sea-level rises). In the absence of mitigation, they find that the area at risk by $2100\left(708,000 \mathrm{~km}^{2}\right)$ is not much different from that in the mitigation scenario, but increases to $1,630,000 \mathrm{~km}^{2}$ by 2300 , which is three times the area at risk today.

In the third component of Brown and colleagues' study, the authors consider the number of people at risk from coastal flooding. If global warming is kept to $1.5^{\circ} \mathrm{C}$, they find that $1.5-2.1 \%$ of the global population will be exposed to a 1 -in-100-year coastal flooding by 2100 , compared with $4.3-5.4 \%$ of the global population in the non-mitigation scenario. In other words, more than half of the potential population exposure can be avoided by 2100 if global warming is capped. It is important to keep in mind, however, that population exposure does not depend only on the amount of sea-level rise - the number of people exposed could decrease if people move away from the coast, for example.

Given that sea levels will rise irrespective of future global temperature changes, Brown et al. stress that at least some action will need to be taken to adapt. However, their calculations of the land area exposed to sea-level rise do 


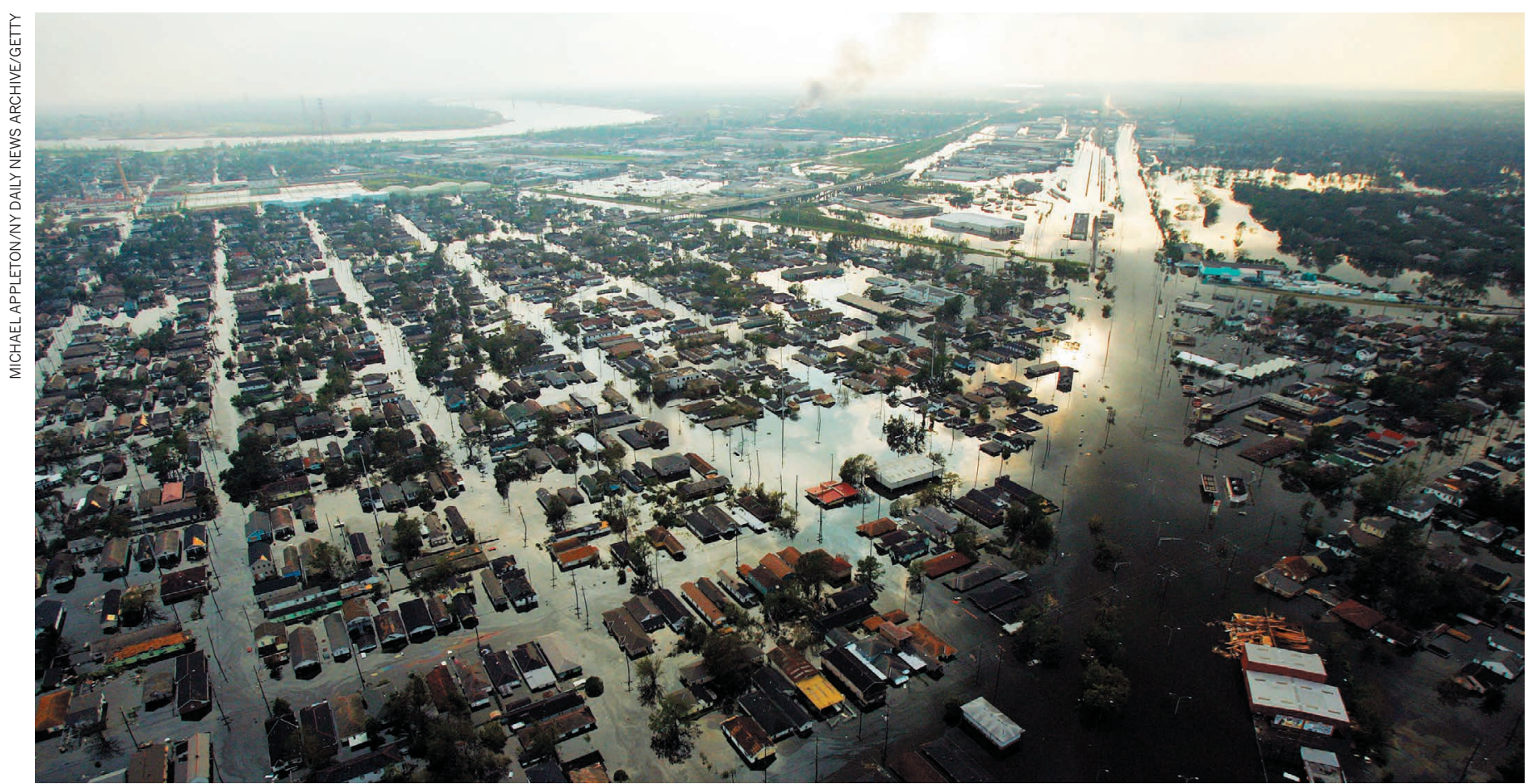

Figure 1 | Flooding in New Orleans, Louisiana, after Hurricane Katrina, 2005. Brown et $_{\text {al. }}{ }^{2}$ report that flooding events, such as that caused by Hurricane Katrina, will affect more land and people in the future as a result of sea-level rises associated with global warming.

not consider the effects of coastal-protection measures, such as the construction of dykes or dunes. If such measures were considered in the analysis, then the area and number of people exposed would change. Moreover, the construction of coastal defences will be largely driven by economic considerations, which will be different for different countries.

The authors define land at risk from sealevel rise as the 1-in-100-year coastal floodplain. But will people be driven away from such land by the infrequent floods, or will they accept the occasional inundation, moving away only temporarily as needed? It might be better to consider the area of land that will become permanently flooded to make a moredirect estimate of the population that will be exposed to sea-level rise.

A limitation of the study is that Greenland, Antarctica and all glaciers elsewhere are lumped together as the land ice that contributes to sea-level rise. However, ice will probably melt at different rates in each of these regions. This will cause the relative contributions of the different sources to change over time. One way to improve the regional estimates of sea-level rise would therefore be to scale the contributions of the ice sheets according to their individual effects.

Nevertheless, studies such as those of Brown and colleagues are essential, because they show the complexity of the climate system's response to change and how this affects society. By directly connecting the effects of climate change to the consequences for humans, the authors clearly show that climate mitigation needs to happen now for a better future.
Aimée Slangen is in the Department of Estuarine and Delta Systems, NIOZ Royal Netherlands Institute for Sea Research and Utrecht University, 4401 NT Yerseke, the Netherlands.

e-mail:aimee.slangen@nioz.nl
1. McGranahan, G., Balk, D. \& Anderson, B. Environ. Urban. 19, 17-37 (2007).

2. Brown, S. et al. Earth's Future 6, 583-600 (2018).

3. Goodwin, P. Clim. Dyn. 47, 2219-2233 (2016).

4. Slangen, A. B. A. et al. Clim. Change 124, 317-332 (2014).

5. Vafeidis, A. T. et al. J. Coast. Res. 24, 917-924 (2008).

\section{GENE REGULATION}

\section{A new phase in transcription}

\section{A subunit of the enzymatic complex $\mathrm{P}$-TEFb can induce compartmentalization of proteins into liquid-like droplets in cells. This phase separation might help P-TEFb to promote gene transcription. SEE LETTER P.318}

\section{JAMES A. GOODRICH \& DYLAN J. TAATJES}

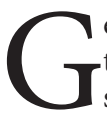
enomic DNA is not indiscriminately transcribed into RNA. Instead, select sequences are transcribed at any given time or in any given cell type. How this process is regulated has been an active area of research for decades, because of its complexity and importance in embryonic development and disease. On page 318, Lu et al. ${ }^{1}$ describe an aspect of transcription regulation that involves liquid-liquid phase separation - a process by which proteins, nucleic acids and other molecules self-organize into liquid-like droplets to enable subcellular compartmentalization.

Transcription is catalysed by the enzyme
RNA polymerase II (Pol II). The activity of Pol II is, in turn, regulated by a complex called $\mathrm{P}-\mathrm{TEFb}$, which consists of the protein cyclin T1 (CCNT1) and the kinase enzyme CDK9. P-TEFb binds to the carboxy-terminal domain (CTD) of Pol II (ref. 2) - this domain consists of 52 repeats of 7 amino acids, 5 of which can be phosphorylated. The CCNT1 subunit regulates the activity of CDK9, which can phosphorylate the Pol II CTD many times to help control Pol II function ${ }^{3}$.

Lu et al. first investigated which region of CCNT1 is responsible for regulating CDK9 activity. They found that mutations in a domain of CCNT1 rich in the amino acid histidine led to defects in the activation of 